\title{
Lithium reduces tumorigenic potential in response to EGF signaling in human colorectal cancer cells
}

\author{
FLÁVIA VIDAL, WALLACE MARTINS DE ARAUJO, ANDRÉ L.S. CRUZ, \\ MARCELO NEVES TANAKA, JOÃO P.B. VIOLA and JOSÉ A. MORGADO-DÍAZ \\ Divisão de Biologia Celular, Centro de Pesquisas, Instituto Nacional do Câncer, \\ Rua André Cavalcanti 37, $5^{\circ}$ Andar, Rio de Janeiro CEP 20230-051, Brazil
}

Received November 29, 2010; Accepted January 28, 2011

DOI: $10.3892 /$ ijo.2011.955

\begin{abstract}
Lithium is a specific inhibitor of GSK3- $\beta$, and hence, an activator of the Wnt/ $\beta$-catenin pathway, whereas the epidermal growth factor (EGF) has been linked to malignant transformation in epithelial cancer cells. Both pathways are aberrantly activated in most colorectal cancers (CRCs). However, the relationship between them in modulating events related to the progression of this cancer type remains to be defined. In this study, we investigated whether the Wnt/ $\beta$-catenin and EGFR pathways converge to modulate the malignant potential of CRC. We used Caco-2 cells, a well-established model used to study CRC, and treatments with lithium chloride, as a modulator of the Wnt/ $\beta$-catenin pathway, and with EGF as an inducer of EGFR signaling. We found that both agents altered the subcellular distribution of claudin- 1 and $\beta$-catenin, two important proteins of the apical junctional complex, but not their abundance in the cell. Nuclear stabilization of $\beta$-catenin, a marker of Wnt pathway activation, was observed after treatment with both compounds. However, lithium, but not EGF, inhibited GSK3- $\beta$, indicating that these agents modulate this enzyme in a differential fashion. Furthermore, EGF treatment increased the proliferative and migratory capacity but did not alter the colony formation potential of these cells. Surprisingly, lithium, known to activate the $\mathrm{Wnt} / \beta$-catenin pathway, inhibited the increased proliferation by arresting cells in the $\mathrm{G}_{2} / \mathrm{M}$ phase as well as the cell migration promoted by EGF, as demonstrated by the combined treatment with these agents. Lithium treatment alone reduced the cell colony formation. Thus, our findings suggest that lithium plays an important role in regulating cellular events related to tumor progression in CRC.
\end{abstract}

Correspondence to: Dr José A. Morgado-Díaz, Divisão de Biologia Celular, Centro de Pesquisas, Instituto Nacional do Câncer, Rua André Cavalcanti 37, $5^{\circ}$ Andar, Rio de Janeiro CEP 20230-051, Brazil

E-mail: jmorgado@inca.gov.br

Key words: cell-cell adhesion, cell cycle, colorectal cancer, epidermal growth factor, lithium, tumor progression, wnt/ $\beta$-catenin pathway

\section{Introduction}

Adherens junctions (AJs) and tight junctions (TJs) form the apical junctional complex (AJC) in epithelial cells. This complex is responsible for cell-cell adhesion and the maintenance of epithelial barrier integrity and is involved in cell signaling events $(1,2)$. In colorectal cancer $(\mathrm{CRC})$, constituent molecules of the AJC, including $\beta$-catenin and claudin proteins, have been associated with colorectal tumor progression (3). Certain studies have shown that the free form of $\beta$-catenin, unbound to E-cadherin, accumulates in the cytoplasm, which potentiates its translocation into the nucleus, increasing the transcriptional activity of genes related to CRC progression (4). In addition, nuclear localization of $\beta$-catenin is a hallmark of $\mathrm{Wnt} / \beta$-catenin pathway activity, which is aberrantly activated in approximately $90 \%$ of all CRC cases (5). It should be noted, that the altered expression or subcellular localization of claudin, the main protein present in TJs, is frequently observed in a variety of human tumors, including CRC (6-10). However, the exact roles that $\beta$-catenin and claudin proteins play in cell signaling pathways underlying malignant transformation in this kind of cancer remain to be defined. This is of particular interest as CRCs expressing these proteins are the fourth most common malignant tumor type worldwide (11).

The epidermal growth factor (EGF) plays many important roles in normal epithelial cells. For example, it has been demonstrated that EGF modulates TJs in a very selective way; while EGF induces the synthesis of claudin- 4 through the ERK1/2 pathway, it inhibits that of claudin-2 $(4,12,13)$. A number of signaling events induced by EGF have also been linked to changes in cell morphology, including plasma membrane ruffling and cell rounding, both of which are required for cancer progression (14). The aberrant activation of EGFR can affect cell-cell adhesion by disrupting the association between E-cadherin and $\beta$-catenin, leading to a loss of cell differentiation and increased rates of proliferation and migration, all of which are known hallmarks of cancer progression (15). A link between growth factor signaling and AJC disassembly and the subsequent increased cell migration and invasiveness during tumor progression, has been reported $(16,17)$. It has been demonstrated that the EGFR and Wnt/ $\beta$ catenin pathways might interact in the same way to modulate 
these events as EGFR activates various downstream kinases, which could modulate the phosphorylation status of GSK3- $\beta$ and, consequently, activate the $\mathrm{Wnt} / \beta$-catenin pathway (18-20). However, there are still controversies concerning this issue as certain authors did not find a relation between these two pathways in events related to cancer progression $(21,22)$.

Lithium is a specific and non-competitive inhibitor of GSK3- $\beta$ in vitro and in vivo, and consequently it is an activator of the Wnt/ $\beta$-catenin pathway (23). This drug promotes and/or inhibits cell cycle progression and proliferation by inhibiting GSK3- $\beta$ depending on the cell type (24-27). Nevertheless, whether lithium modulates events related to CRC progression remains unknown. Thus, as the EGFR and Wnt/ $\beta$-catenin signaling pathways play important roles in CRC development, we hypothesize that there is a link between these two pathways in mediating crucial events in this cancer type. To test this hypothesis, we used Caco- 2 cells as a CRC model and different treatments with EGF and lithium, and the effects of these agents on cell-cell adhesion, proliferation, cell cycle, migration and cell colony formation, were monitored.

In this study, we present evidence that EGF and lithium treatments induce the internalization of claudin- 1 and $\beta$-catenin from cell-cell contacts to the cytoplasm, as well as a marked localization of $\beta$-catenin in the nucleus. Furthermore, we observed that lithium, but not EGF, inhibited GSK3- $\beta$, as determined by increased levels of phospho-GSK3- $\beta$ (Ser9). Surprisingly, although this later event suggests Wnt/ $\beta$-catenin pathway activation, reduced proliferation, migration and colony formation were observed. Additionally, lithium inhibited the increase in cell proliferation and migration caused by EGF. Finally, cell cycle distribution analysis demonstrated that cells treated with lithium clearly showed an arrest in the $\mathrm{G}_{2} / \mathrm{M}$ phase. Therefore, our results suggest that lithium plays an important role in regulating cellular events related to tumor progression in CRC and may represent a novel therapeutic agent in the treatment of this disease.

\section{Materials and methods}

Materials. Rabbit polyclonal anti-claudin-1, rabbit polyclonal anti- $\beta$-catenin (clone CAT-5H10) and mouse monoclonal anti$\alpha$-tubulin (clone Z022) antibodies were purchased from Zymed Laboratories, Inc. (San Francisco, CA, USA). Rabbit monoclonal anti-GSK3- $\beta$ (clone 27C10) and rabbit polyclonal anti-phospho-GSK3- $\beta$ (Ser9) were purchased from Cell Signaling Technology (Danvers, MA, USA). Mouse monoclonal anti-human lamin B (clone 101-B7) was purchased from Calbiochem (Darmstadt, Germany). The secondary antibodies, peroxidase-conjugated goat anti-rabbit IgG and goat anti-mouse IgG, were obtained from Zymed. Alexa 488-conjugated goat anti-rabbit IgG and Alexa 546-conjugated goat anti-mouse IgG were purchased from Molecular Probes (Eugene, OR, USA). EGF was purchased from Invitrogen (Carlsbad, CA, USA) and lithium chloride (LiCl) from Sigma Chemical Co. (St. Louis, MO, USA).

Cell culture and treatments. Caco-2 cells (ATCC, no. HTB-37, Rockville, MD, USA), a human colon adenocarcinoma cell line, were grown in Dulbecco's Modified Eagle's medium (DMEM) (Invitrogen) supplemented with $10 \%$ fetal bovine serum, penicillin $\mathrm{G}(60 \mathrm{mg} / \mathrm{l})$ and streptomycin $(100 \mathrm{mg} / \mathrm{l})$ at $37^{\circ} \mathrm{C}$ in a humidified atmosphere of $5 \% \mathrm{CO}_{2}$ /air.

Before treatments, cells were grown in serum-free DMEM for $24 \mathrm{~h}$, then, EGF and/or $\mathrm{LiCl}$ at a final concentration of $100 \mathrm{ng} / \mathrm{ml}$ and $50 \mathrm{mM}$, respectively, were added to the culture medium for 24,48 , or $72 \mathrm{~h}$. The used drug concentrations were based on previous studies $(6,28)$ and as they did not alter the cell viability of Caco-2 cells, they were used in this study.

Differential extraction in TX-100 and total cell lysates. For differential cell extraction in Triton X-100, samples were rinsed three times in phosphate-buffered saline (PBS) and incubated for $20 \mathrm{~min}$ at $4^{\circ} \mathrm{C}$ in cytoskeletal extraction buffer [50 mM NaCl, $10 \mathrm{mM}$ Pipes (pH 6.8), 3 mM $\mathrm{MgCl}_{2}, 0.5 \%$ Triton X-100, $300 \mathrm{mM}$ sucrose, $1 \mathrm{mM}$ orthovanadate, $20 \mathrm{mM}$ $\mathrm{NaF}$, and protease inhibitors]. Cells were scraped from plates, homogenized, and centrifuged at $10,000 \mathrm{x}$ g for $10 \mathrm{~min}$ at $4^{\circ} \mathrm{C}$. The supernatant corresponding to the Triton X-100-soluble fraction (actin cytoskeleton-unlinked proteins) was removed and stored at $-20^{\circ} \mathrm{C}$. The pellet was resuspended in SDS buffer [20 mM Tris- $\mathrm{HCl}$ (pH 7.5), 5 mM EDTA, and 2.5 mM EGTA, $1 \% \mathrm{SDS}]$ and boiled at $100^{\circ} \mathrm{C}$ for $10 \mathrm{~min}$. After centrifugation for $10 \mathrm{~min}$ at $10,000 \mathrm{x} \mathrm{g}$, the supernatant corresponding to the Triton X-100 insoluble fraction (actin cytoskeleton-linked proteins), was gently removed and stored at $-20^{\circ} \mathrm{C}$.

Total cell lysates were obtained by incubating the cells in lysis buffer [1\% Triton X-100, 0.5\% sodium deoxycholate, $0.2 \%$ SDS, $150 \mathrm{mM} \mathrm{NaCl}, 2 \mathrm{mM}$ EDTA, $10 \mathrm{mM}$ Hepes (pH 7.4), $20 \mathrm{mM} \mathrm{NaF}, 1 \mathrm{mM}$ orthovanadate and a protease inhibitor cocktail (1:100 dilution)], for $30 \mathrm{~min}$ at $4^{\circ} \mathrm{C}$. After centrifugation at $10,000 \mathrm{x} \mathrm{g}$ for $10 \mathrm{~min}$ at $4^{\circ} \mathrm{C}$, the supernatant was removed and stored at $-20^{\circ} \mathrm{C}$ for subsequent analysis.

Subcellular fractionation. After the different treatments, subcellular fractions were obtained using a classic cell fractionation methodology. Briefly, cells were homogenized with 30-60 strokes using a Potter-type homogenizer in lysis buffer (10 mM Tris- $\mathrm{HCl}, \mathrm{pH} 7.5,250 \mathrm{mM}$ sucrose, $1 \mathrm{mM} \mathrm{MgCl}_{2}$ containing $1 \mathrm{mM}$ orthovanadate, $20 \mathrm{mM} \mathrm{NaF}$, and protease inhibitor cocktail). The homogenate was centrifuged at 3,000 $\mathrm{x} \mathrm{g}$ for $10 \mathrm{~min}$, and the resulting pellet represented the nuclear fraction. The supernatant was centrifuged at 30,000 x g for $1 \mathrm{~h}$, and the supernatant corresponding to the cytoplasmic fraction was collected. The nuclear fraction was further treated with hypertonic buffer $(20 \mathrm{mM}$ Hepes-KOH, $\mathrm{pH} 7.9$, $25 \%$ glycerol, $420 \mathrm{mM} \mathrm{NaCl}, 1.5 \mathrm{mM} \mathrm{MgCl}, 0.2 \mathrm{mM}$ EDTA, $0.5 \mathrm{mM}$ DTT containing $1 \mathrm{mM}$ orthovanadate, $20 \mathrm{mM} \mathrm{NaF}$, and protease inhibitor cocktail) for $20 \mathrm{~min}$ with constant vortexing at $4^{\circ} \mathrm{C}$ and was then centrifuged at $30,000 \times \mathrm{g}$ for $1 \mathrm{~h}$. The supernatant containing nuclear proteins was collected and stored at $-20^{\circ} \mathrm{C}$ for later analysis. All cellular fractionation steps were carried out at $4^{\circ} \mathrm{C}$. Nuclear and cytoplasmic fractions were confirmed by Western blot analysis using anti-lamin B and anti-I $\kappa \mathrm{B}$ antibodies, respectively.

Western blot analysis. Equal amounts of cell protein (30-40 $\mu \mathrm{g} /$ lane), quantified by the BCA protein assay kit (BioRad, Hercules, CA, USA), were electrophoretically separated by SDS-PAGE in $10-12 \%$ gels and transferred to nitrocellulose membranes using a semi-dry transfer cell (BioRad) at $10 \mathrm{~V}$ for $60 \mathrm{~min}$. 
Membranes were blocked for $1 \mathrm{~h}$ with TBS-T (20 mM Tris- $\mathrm{HCl} \mathrm{pH} 7.6,137 \mathrm{mM} \mathrm{NaCl}$ and $0.1 \%$ Tween-20) containing $5 \%$ low-fat dried milk or with $1 \%$ BSA (Sigma) and incubated overnight with primary antibodies: Anti-claudin-1, anti- $\beta$ catenin, anti-GSK3- $\beta$ and anti-phospho-GSK3- $\beta$ (Ser9). After washing, membranes were incubated for $1 \mathrm{~h}$ with peroxidaseconjugated goat anti-rabbit IgG or peroxidase-conjugated goat anti-mouse IgG. Proteins were visualized using an enhanced chemiluminescence kit (GE Healthcare). Band images of three independent experiments were quantified by optical density using the Lab-Works 4.6 software (BioRad). $\alpha$-tubulin was used as the loading control for each protein.

Immunofluorescence. Cells were plated on coverslips that had been placed into 24-well plates in advance. After treatment, they were washed in PBS supplemented with $100 \mathrm{mM} \mathrm{CaCl}_{2}$ and $100 \mathrm{mM} \mathrm{MgCl}_{2}$ (PBS/CM) and fixed in $4 \%$ paraformaldehyde for $5 \mathrm{~min}$. Samples were permeabilized with $0.5 \%$ TX-100 in PBS for $10 \mathrm{~min}$. Later, cells were incubated in $50 \mathrm{mM} \mathrm{NHCl}$ in PBS for 10 min and blocked in 3\% BSA for $1 \mathrm{~h}$. Cells were incubated at $37^{\circ} \mathrm{C}$ with the primary antibodies, anti- $\beta$-catenin and anti-claudin- 1 , for $1 \mathrm{~h}$, followed by a further $1 \mathrm{~h}$ with secondary Alexa 488-conjugated anti-rabbit, or Alexa 546-conjugated anti-mouse antibodies. The coverslips were washed in PBS and mounted with $n$-propyl-gallate, and cell staining was detected using an Axio Observer Z1 immunofluorescence microscope equipped with an Axiocam HRc Rev. 3 camera and Axiovision Release 4.8.1 image analyzer program (Carl Zeiss Inc., Germany).

Cell proliferation assay. The crystal violet method was used to measure cell proliferation. Cells $\left(2 \times 10^{4}\right.$ cell $\left./ \mathrm{ml}\right)$ were cultured in 96-well plates in the presence or absence of EGF and/or lithium for 24, 48 and $72 \mathrm{~h}$ before being fixed with ethanol for $10 \mathrm{~min}$. A crystal violet solution $(0.05 \%$ crystal violet and $20 \%$ methanol) was added for $10 \mathrm{~min}$. Cells were washed twice with water and then solubilized with methanol. The absorbance at $595 \mathrm{~nm}$ was measured with a Spectra Max 190 spectrophotometer (Molecular Devices, Sunnyvale, CA, USA).

Flow cytometry. Cells $\left(4 \times 10^{5} \mathrm{cell} / \mathrm{ml}\right)$ were cultured in six-well microtiter plates and treated for $24 \mathrm{~h}$ with EGF and/or lithium After this period cells were harvested by trypsinization and washed once with ice-cold PBS. The cells were then stained in the dark with $75 \mu \mathrm{M}$ propidium iodide (Sigma) for at least $30 \mathrm{~min}$ in the presence of NP-40. Analysis of the DNA content was carried out by collecting 10,000 events for cell cycle and sub- $\mathrm{G}_{1}$ analysis using a FACScalibur flow cytometer and CellQuest software (BD Biosciences, San Jose, CA, USA).

Wound-healing assay. Caco-2 cells were seeded into six-well plates until confluence. Cell monolayers were manually wounded by scraping with a pipette tip to perform a woundhealing assay. For each plate, 3-5 wounds were made and three sites of regular wounds, verified under a microscope, were selected and marked. After washing with PBS, cells were incubated at $37^{\circ} \mathrm{C}$ in SFB-free DMEM containing EGF and/or lithium. Cells were permitted to migrate into the denuded area for $24 \mathrm{~h}$. Immediately after wounding and at the end of the experiment, wounds were photographed and the cell migration of untreated and treated cells into the wounds was evaluated. The distance of cell migration into the wounded area from three independent experiments was quantified.

Colony formation assay. Caco- 2 cells $\left(5 \times 10^{3}\right.$ cells $\left./ \mathrm{ml}\right)$ were plated on a 12-well plate and incubated for $4 \mathrm{~h}$ under culture conditions to allow cell adherence. Cultures were treated with EGF and/or lithium for 10 days to assess the clonogenic potential at low seeding density. The culture medium was changed every two days and the formation of cell colonies was visualized by staining with $0.05 \%$ violet crystal and quantified at $595 \mathrm{~nm}$ using the Spectra Max 190 spectrophotometer.

Statistical analysis. The data from Western blot analysis, wound-healing and colony formation assays were analyzed statistically by one-way analysis of variance (ANOVA), followed by Dunnett's post tests. Proliferation assay statistics were performed by two-way analysis of variance (ANOVA) followed by Bonferroni post tests. Both analyses were performed using GraphPad Prism version 4.0 for Windows (GraphPad Software, San Diego, CA). The data were obtained from at least three independent experiments and expressed as the means \pm SD. Differences were considered to be significant for values of $\mathrm{p}<0.05$.

\section{Results}

EGF and lithium induce $\beta$-catenin and claudin-1 redistribution . Initially, we analyzed the effects of EGF and lithium on the subcellular localization of $\beta$-catenin and claudin- 1 after $24 \mathrm{~h}$ of treatment. We observed that the drugs caused the redistribution of both proteins, as observed by immunofluorescence (Fig. 1A-B). In the control cells, a typical honeycomb AJC protein staining pattern was observed. An apparent $\beta$-catenin localization in the nucleus and the internalization of claudin-1 from the cell membrane to the cytoplasm was observed in the cells treated with EGF, but a small amount still remained at the cell-cell contacts. Lithium treatment caused a stronger effect than EGF on $\beta$-catenin redistribution with some cells presenting absence of this protein in the cell-cell contacts. The effect of lithium treatment on claudin-1 distribution was less than on $\beta$-catenin. Additionally, an elongation of the cells was observed when the cells were treated with lithium. In the cells treated with EGF plus lithium an apparent recovery at the cell-cell contacts of $\beta$-catenin was observed, but the protein still remained in the nuclei, and claudin-1 was mostly localized in the cytoplasm. It is known that the functionality of AJC components is dependent on their association with the actin cytoskeleton, which can be assessed by analyzing the localization of AJC proteins in TX-100 insoluble and soluble fractions by Western blot analysis $(29,30)$. Western blot analysis of TX-100 soluble and insoluble fractions showed that lithium but not EGF caused a significant increase in $\beta$-catenin in the TX-100 soluble fraction compared to the untreated cells. Co-treatment with EGF and lithium synergistically induced a shift of $\beta$-catenin from the TX-100 insoluble to the TX-100 soluble fraction as was observed when comparing cells treated with lithium only. In addition, all the treatments caused 
A
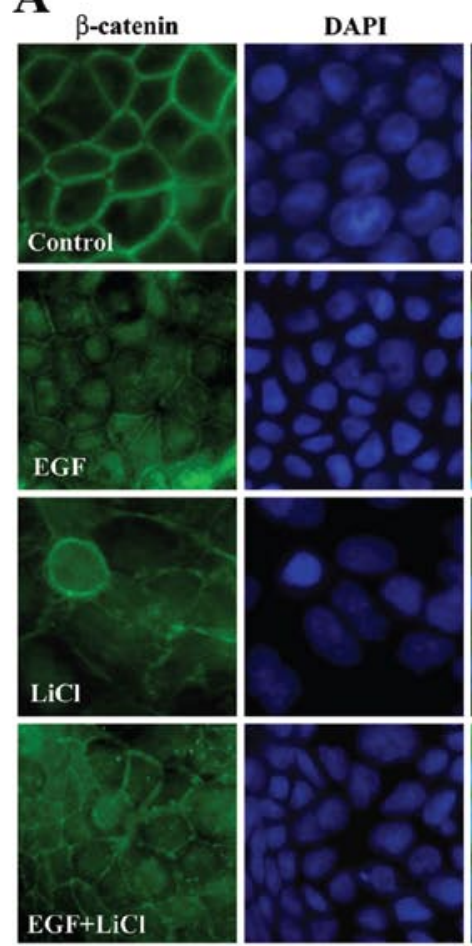

C

$\beta$-catenin

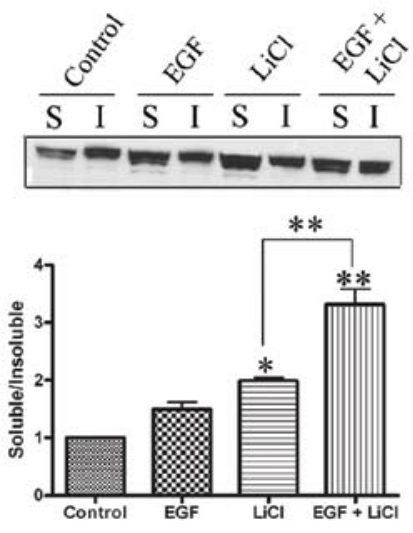

B
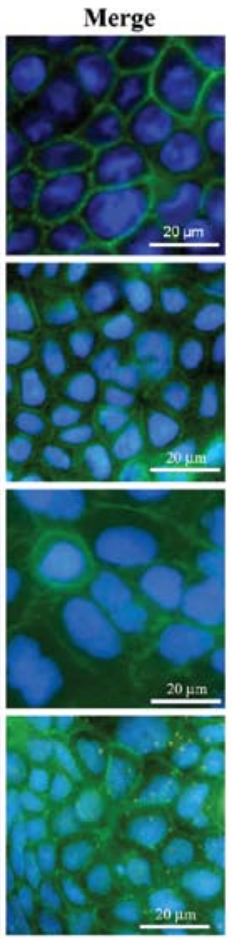

DAPI
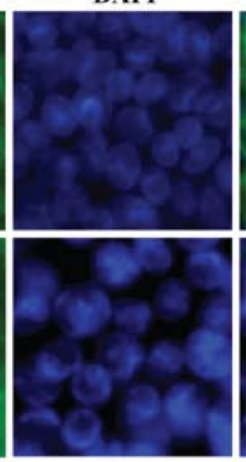

EGF
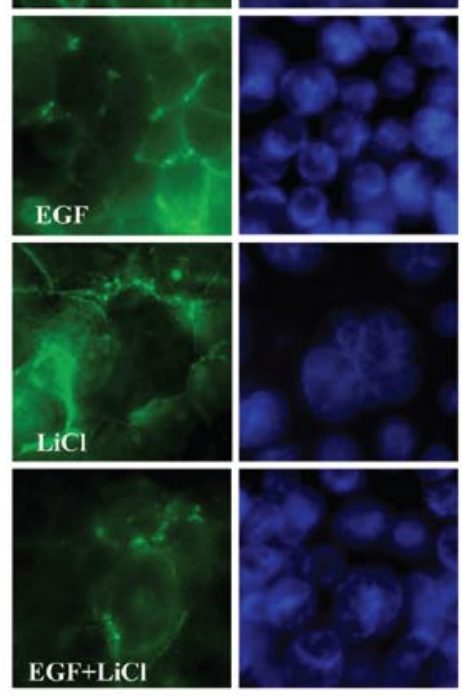
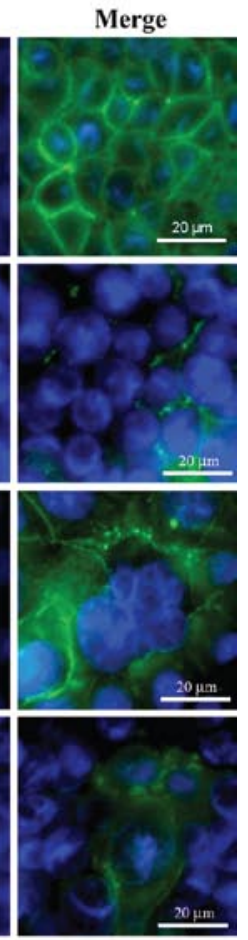

\section{Claudin-1}
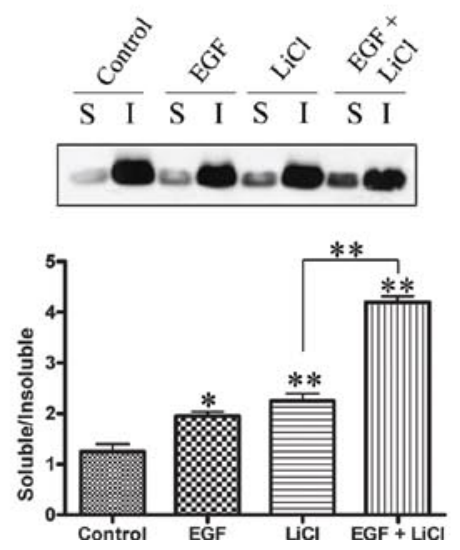

Figure 1. EGF and lithium induce $\beta$-catenin and claudin-1 redistribution. Caco-2 cell monolayers were treated with $100 \mathrm{ng} / \mathrm{ml} \mathrm{EGF}$ and/or $50 \mathrm{mM} \mathrm{LiCl} \mathrm{for}$ $24 \mathrm{~h}$ and were then prepared for immunofluorescence and Western blot analysis, as described in the Materials and methods section. (A and B) Immunofluorescence analysis showing the labeling profiles of $\beta$-catenin and claudin-1, respectively after the respective treatments. (C) Western blot and densitometry analyses showing that both proteins were significantly increased in the TX-100 soluble fractions after treatment with the drugs. Co-treatment had a synergistic effect on the altered localization of the proteins. In each case, the score was calculated using the following equation: Arbitrary score $=($ amount of the protein in the soluble fraction)/(amount of the protein in the insoluble fraction). The score for control cells was normalized to 1 in each case. The results are expressed as the means $\pm \mathrm{SD}$ of three independent experiments. ${ }^{*} \mathrm{p}<0.05,{ }^{* *} \mathrm{p}<0.01$.

claudin protein distribution in the TX-100 soluble fractions (Fig. 1C).

EGF and lithium did not alter the cell content of $\beta$-catenin and claudin-1 proteins but lead to nuclear $\beta$-catenin stabilization . As shown in Fig. 1, the drugs caused an alteration of protein localization, which led us to analyze the cell protein content after the respective treatments. We observed by Western blot analysis that treatment with each drug alone or in combination did not affect the cell content of $\beta$-catenin and claudin-1
(Fig. 2A). To confirm $\beta$-catenin labeling in the nucleus after treatment with EGF and/or lithium, subcellular fractionation was used to obtain representative nuclear and cytoplasmic cell fractions. Using these fractions and Western blot analysis, we observed the major localization of $\beta$-catenin in the nuclear fraction of cells treated with both agents separately. However, no synergistic effect was observed when cells were treated with EGF and lithium. In addition, a major localization of $\beta$-catenin at the cytoplasmic fraction was observed when the cells were treated with lithium or EGF plus lithium. Additionally, 
A

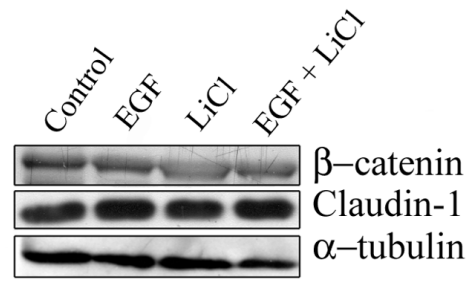

$\beta$-catenin

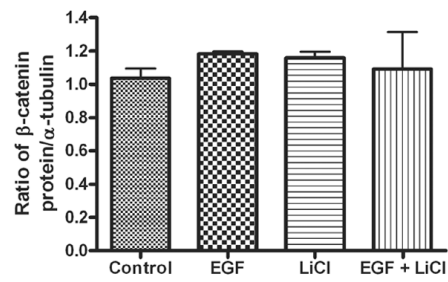

Claudin-1

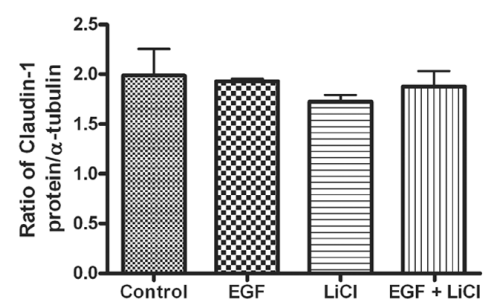

\section{B}

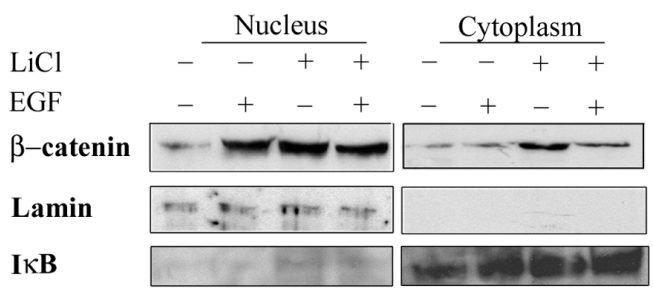

Nucleus

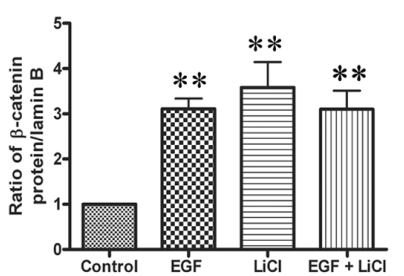

Cytoplasm

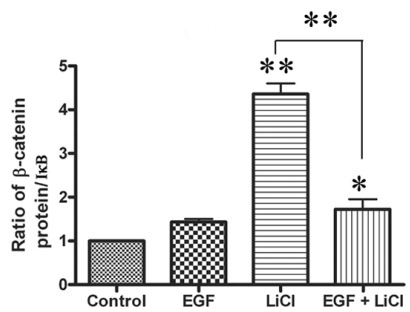

Figure 2. EGF and lithium did not alter the cell content of $\beta$-catenin and claudin-1 proteins but led to nuclear $\beta$-catenin stabilization. (A) Western blot and densitometry analyses showing that treatment with the drugs did not alter the cell content of the analyzed proteins. (B) Subcellular fractions of Caco-2 cells were prepared and cytoplasmic and nuclear proteins were analyzed using an antibody against $\beta$-catenin. The drugs led to nuclear $\beta$-catenin stabilization and cytoplasmic localization of the protein, and this was observed only for cells treated with $\mathrm{LiCl}$ or $\mathrm{EGF}+\mathrm{LiCl}$. The results represent the means $\pm \mathrm{SD}$ of three independent experiments. ${ }^{*} \mathrm{p}<0.05,{ }^{* *} \mathrm{p}<0.01$.
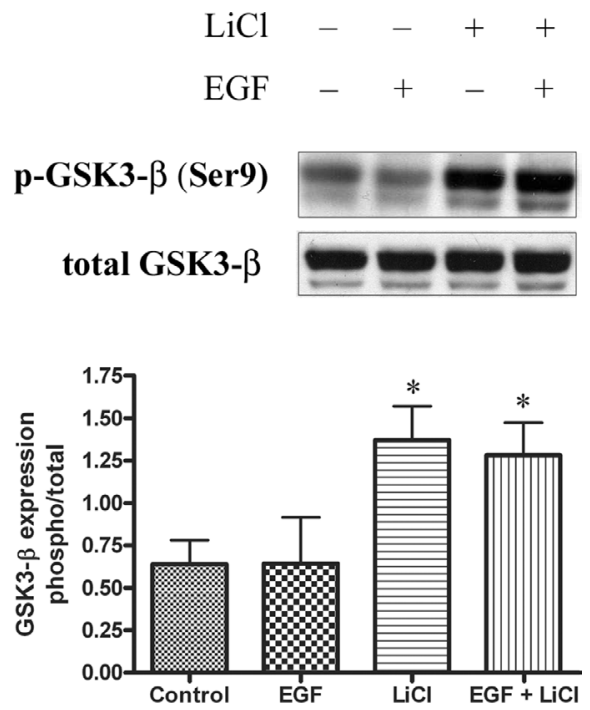

Figure 3. $\mathrm{LiCl}$ and EGF induce differential modulation of GSK3- $\beta$ activity. Western blot and densitometry analyses showed that p-GSK3- $\beta$ levels increased after $\mathrm{LiCl}$ or EGF $+\mathrm{LiCl}$ treatments, but not with EGF. Results represent the means $\pm \mathrm{SD}$ of three independent experiments. " $\mathrm{p}<0.05$.

the effect of EGF plus lithium on the cytoplasmic localization of $\beta$-catenin was less effective than the lithium treatment alone (Fig. 2B).

Nuclear $\beta$-catenin stabilization caused by lithium and EGF is mediated differentially by GSK3- $\beta$. Our results showing that EGF treatment caused the translocation of $\beta$-catenin to the nucleus, prompted us to investigate whether the trans- location of this protein was due to GSK3- $\beta$ inhibition as has been observed by others. Fig. 3 shows that treatment with lithium is associated with an increased level of GSK3- $\beta$ phosphorylation (Ser9 residue), suggesting the activation of the Wnt/ $\beta$-catenin pathway. Increased phospho-GSK3- $\beta$ (Ser9) levels were also observed in the cells treated with EGF and lithium but not after EGF treatment alone. Therefore, even though EGF caused nuclear $\beta$-catenin translocation, these results indicate that it occurs through a GSK3- $\beta$ independent mechanism.

Lithium treatment inhibits proliferation concomitantly with $G_{2} / M$ cell cycle arrest. Epithelial tumor cells with metastatic potential require changes of the cell phenotype, such as an increase in cell proliferation, migration and tumorigenic potential rates (31). In this context, genes such as $c$-myc and cyclin Dl can be upregulated through the Wnt pathway (5). As lithium is known to activate the Wnt pathway, an increase in Caco- 2 cell proliferation could be expected when cells are treated with this agent. Therefore, in order to analyze whether lithium affects the growth capacity of Caco- 2 cells, we performed a proliferation assay and measured crystal violet incorporation, which correlates with total cell number. We observed that EGF increased the cell number after 48 and $72 \mathrm{~h}$ of treatment, compared to the untreated cells. Surprisingly, lithium treatment inhibited cell growth at 24, 48 and $72 \mathrm{~h}$, and the same effect was observed in the cells treated with EGF plus lithium. For instance, cells treated with EGF and lithium for $24 \mathrm{~h}$ presented a strong decrease in cell number compared to the cells treated with EGF alone. This result suggests an inhibitory effect of lithium on the increased cell number caused by EGF (Fig. 4A). 
A

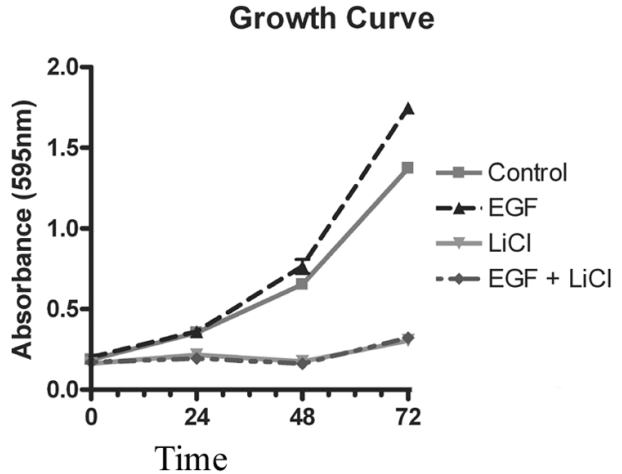

B

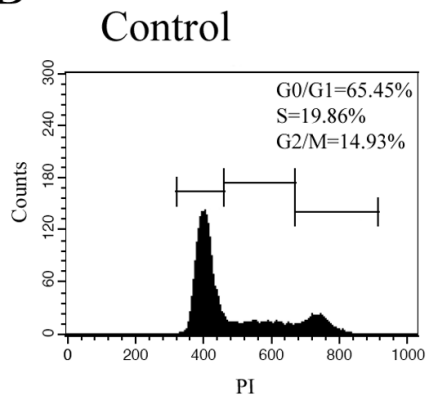

$\mathrm{LiCl}$

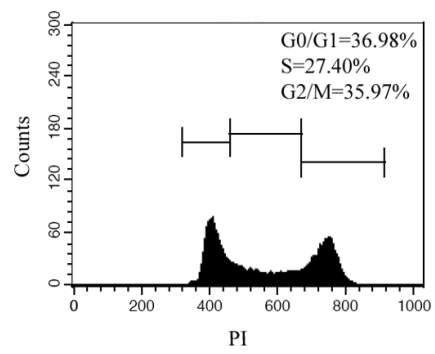

EGF

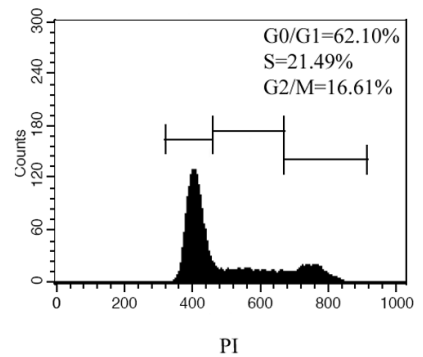

$\mathrm{EGF}+\mathrm{LiCl}$

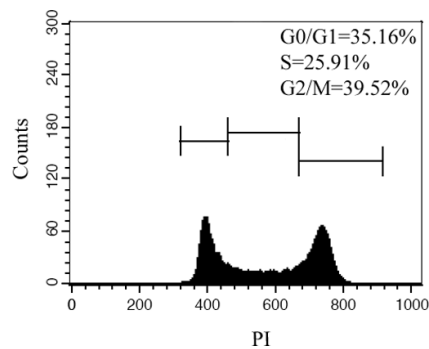

Figure 4. $\mathrm{LiCl}$ treatment inhibits proliferation concomitantly with $\mathrm{G}_{2} / \mathrm{M}$ cell cycle arrest in Caco-2 cells. (A) Growth curves plotted for proliferation assays using violet crystal showed that EGF increased cell proliferation at $48 \mathrm{~h}(\mathrm{p}<0.01)$ and accentuated this effect at $72 \mathrm{~h}(\mathrm{p}<0.001)$. LiCl strongly inhibited Caco-2 cell proliferation after $24 \mathrm{~h}(\mathrm{p}<0.001)$ and also inhibits the EGF-mediated proliferation $(\mathrm{p}<0.001)$, as observed in cells treated with EGF $+\mathrm{LiCl}$ at $24 \mathrm{~h}$. Each point represents the mean \pm SD from three independent experiments. (B) Caco-2 cells were treated as indicated and after $24 \mathrm{~h}$, harvested. The cell cycle profiles were obtained by staining with propidium iodide (PI). Cells treated cells with $\mathrm{LiCl}$ or EGF and $\mathrm{LiCl}$ clearly showed an arrest in the $\mathrm{G}_{2} / \mathrm{M}_{\mathrm{m}} \mathrm{pase}$. The results are representative of three independent experiments.

In order to determine whether the lithium-induced inhibition of Caco-2 cell growth was due to an alteration of cell cycle regulation, cells were then treated with the drugs for $24 \mathrm{~h}$, and cell cycle profiles were monitored by flow cytometric analysis of DNA content. As shown in Fig. 4B, the distribution in the phases of cell cycle indicated that lithium can promote Caco-2 cell progression to $S$ phase and then $G_{2} / M$, in which the population increased when compared to the untreated cells and 24 h-EGF-treated cells. Furthermore, we observed that the percentage of cells in the Sub- $\mathrm{G}_{0}$ phase was very similar to the control group and to all the treatments. Also, in the cells incubated with $\mathrm{NaCl}$, used as the salt control, the percentage of cells was not altered in the different cell cycle phases analyzed (data not shown). Taken together, these results suggest that the growth-inhibitory effect of lithium on Caco- 2 cells could be partly due to its ability to induce $\mathrm{G}_{2} / \mathrm{M}$ cell cycle arrest rather than leading cells to apoptosis-mediated death.

Lithium treatment impairs increased cell motility and clonogenic growth caused by EGF. Cell migration plays a central role in the cancer metastasis process as it regulates tumor progression (21). As the lithium treatment caused the inhibition of EGF-induced cell proliferation, we compared the motility rate of cells treated with EGF and lithium or lithium and EGF in relation to the untreated cells. The rate of wound closure was used to measure cell motility in the wound-healing assay. We observed that $24 \mathrm{~h}$ after EGF treatment, cells presented a higher migratory capacity compared to the control cells. Cells treated with lithium alone had similar cell migration behavior compared to the control cells, and EGF and lithium treatment yielded a decreased migration rate, suggesting that lithium impairs the EGF effect on cell migration (Fig. 5A). The unaltered relative viable cell numbers at $24 \mathrm{~h}$ after EGF treatment in Fig. 4A indicates that cells were effectively migrating and not proliferating. Colony formation assays were used to compare the ability of cells treated and untreated with EGF and lithium to form colonies when plated at sparse densities. We observed that lithium treatment decreased the number of cell colonies induced by EGF after 10 days of treatment. Lithium-inhibited clones had fewer, smaller colonies than EGF-treated cells and control cells. The ability of lithium to inhibit clones from forming colonies was $\sim 57 \%$ compared to the EGF-treated cells. In addition, treatment of cells with EGF plus lithium caused the same effect observed in the cells treated with lithium only, which confirms the inhibitory effect of lithium on EGF (Fig. 5B).

\section{Discussion}

Despite the important roles that growth factor signaling and the Wnt/ $\beta$-catenin pathway play in $\mathrm{CRC}$, the existence of a relationship between them to mediate events related to the progression of this type of cancer remains to be clarified. To address this issue, we treated Caco- 2 cells, a well-defined CRC model, with EGF and with lithium, a GSK3- $\beta$ inhibitor, and analyzed the cell response to these drugs. Initially, we found that both agents and the combination of them induced a significant redistribution of two important AJC proteins, claudin- 1 and $\beta$-catenin, but did not alter their cellular content. 
A

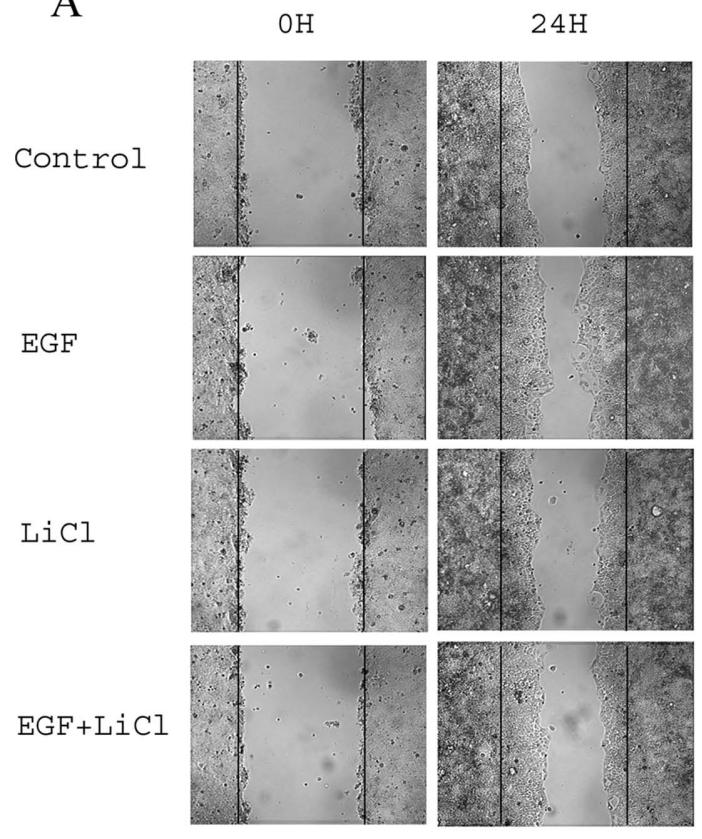

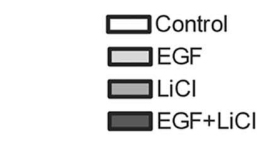

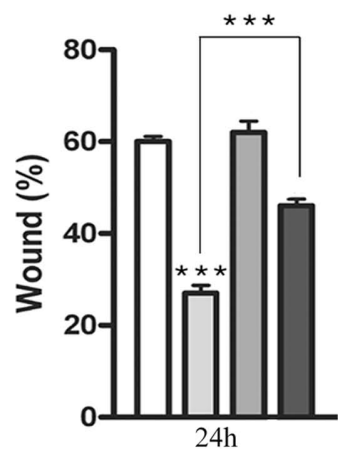

B
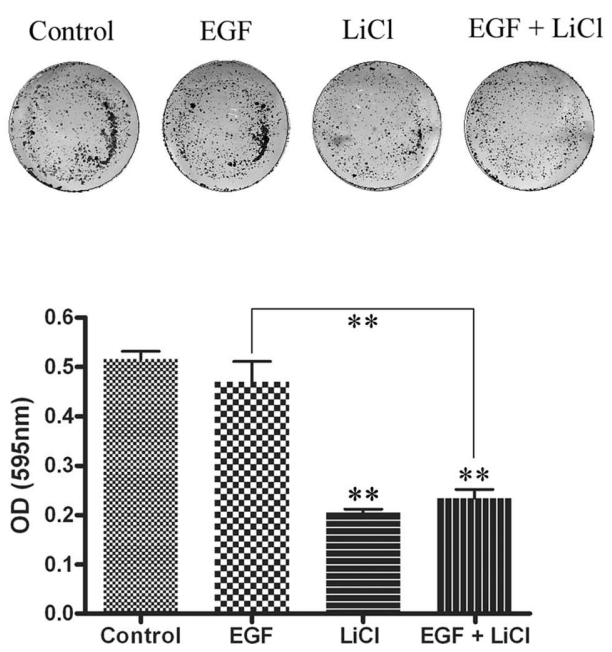

Figure 5. LiCl treatment impairs cell motility and clonogenic growth. (A) Cell motility of untreated cells or cells treated with drugs were examined after $24 \mathrm{~h}$ in wound-healing assays as described in the Materials and methods section. $\mathrm{LiCl}$ treatment at $24 \mathrm{~h}$ not only impaired cell migration, but also inhibited migration caused by EGF, as can be seen in cells treated with $\mathrm{LiCl}$ and EGF. Each point represents the mean of three independent experiments $\pm \mathrm{SD}$. " $\mathrm{p}<0.05$, ${ }^{* *} \mathrm{p}<0.01,{ }^{* * *} \mathrm{p}<0.001$. (B) Cells were plated in 6-well plates at 300 cells/well and treated or not with the drugs as indicated. After 10 days of treatment, cell colonies were visualized following violet crystal staining. Relative cell numbers were then determined by the resultant absorbance at $595 \mathrm{~nm}$. Each point represents the mean $\pm \mathrm{SD}$ of three independent experiments. ${ }^{* *} \mathrm{p}<0.01$.

These results indicate that the treatment of Caco-2 cells with these drugs causes a loss of AJC functionality, which is a prerequisite to cell migration. The effects of EGF on cell content and localization of $\beta$-catenin have previously been described in different cell lines. For example, it was demonstrated that EGF treatment of a human epidermoid cell line resulted in cell-cell contact disassembly and increased transcriptional activity of $\beta$-catenin (17). For ovarian cancer cell lines treated with EGF, the nuclear translocation of $\beta$-catenin and increased migration capacity have also been reported in a recent study (32). The nuclear translocation of $\beta$-catenin was also observed in two colorectal adenocarcinoma cell lines treated with EGF (22). Various studies have described that growth factors can regulate the cell content and localization of different types of claudins, but the machinery of this regulation remains unknown. Using MDCK cells, it was shown that $24 \mathrm{~h}$ of EGF treatment provokes increased transepithelial electrical resistance associated with the synthesis and localization of claudin- 4 at TJs and the simultaneous inhibition of claudin-2 synthesis $(6,12)$. Claudin-1 overexpression provoked migration in human melanoma cells, suggesting a role other than transport (33). Additionally, in human colon cancer tissue samples, increased expression and internalization of claudin-1 from the cell-cell contacts to the cytoplasm and nucleus was observed, suggesting that claudin-1 mislocalization in aggressive tumors correlates with increased migratory capacity $(7,34)$. In the present study, it is possible that $24 \mathrm{~h}$ of EGF treatment have, in fact, produced an important change of 
claudin-1 that is related to increased cell migration but that remained undetected because of the time chosen to measure cellular claudin- 1 content. Thus, our results showing the redistribution of claudin-1 after EGF treatment could explain the more aggressive tumor behavior of Caco- 2 cells.

The translocation of $\beta$-catenin from the cell-cell contacts to the cytoplasm and nuclei after lithium treatment has been observed in some tumor cell lines (35) but not in CRC cell lines. Our results using subcellular fractions and Western blot analysis have shown that EGF and lithium promote a higher labeling of $\beta$-catenin in the nuclear fraction, but that the co-treatment with these agents does not increase the nuclear $\beta$-catenin content. This result can be explained by the differential effect of these compounds on the GSK3- $\beta$ activity. Unlike lithium, EGF did not affect GSK3- $\beta$ activity, and this finding is in conflict with findings observed in other cell lines in which the stimulation of EGFR with EGF promoted GSK3- $\beta$ inhibition $(36,37)$. Thus, based on our finding, it is possible that lithium inactivates GSK3- $\beta$; $\beta$-catenin is not phosphorylated, and therefore accumulates at the cytoplasm for the posterior translocation into the nucleus. In contrast, it is possible that after EGF treatment, GSK3- $\beta$ remains active, then $\beta$-catenin is phosphorylated and degraded. However, a pool of $\beta$-catenin is translocated into the nucleus by an unknown mechanism that is independent of GSK3- $\beta$. Consistent with our results, a study using human epidermoid carcinoma cells showed that treatment with EGF induced nuclear $\beta$-catenin localization, upregulation of $\beta$-catenin-TCF/LEF-1 transcriptional activity, and no significant change in the phosphorylation level of GSK3- $\beta$ (S9) (17). Taken together, our results suggest that EGF could activate the Wnt/ $\beta$-catenin pathway through a GSK3- $\beta$-indepedent mechanism. However, the exact mechanism by which EGF sends $\beta$-catenin to the nucleus remains to be defined. There are no studies showing the effects of lithium on the expression and localization of the TJ protein, claudin-1. In this study, we show for the first time that lithium not only alters $\beta$-catenin localization but also causes the mislocalization of the important TJ protein, claudin-1. The implications of the lithium-mediated effects on this protein in CRC remain to be elucidated.

It is known that EGF binds to EGFR, activating many downstream signaling networks that regulate a multitude of cellular responses, including cell proliferation $(38,39)$. Here, we showed that EGF increased Caco-2 proliferation, but surprisingly, lithium inhibited it, as seen in the case of cotreatment with these two agents. This result was not expected as lithium is known to activate $\mathrm{Wnt} / \beta$-catenin signaling, which in turn activates many target genes responsible for increasing cell proliferation (35). To further investigate this result, we analyzed cell progression through the cell cycle using flow cytometry after the respective treatments. We showed an increase of cells in the $\mathrm{G}_{2} / \mathrm{M}$ phase and a decrease in the $\mathrm{G}_{0} / \mathrm{G} 1$ phase, indicating that lithium could lead to $\mathrm{G}_{2} / \mathrm{M}$ cell cycle arrest. The inhibitory effect on cell proliferation induced by lithium has been observed in different cell lines, but not in CRC cell lines. Inhibited proliferation caused by lithium was observed in a prostate cancer cell line by decreasing the expression of different factors related to DNA replication (26). Additionally, in an esophageal cancer cell line, reduced proliferation induced by lithium occurred through the induction of $\mathrm{G}_{2} / \mathrm{M}$ cell cycle arrest and reduction of cyclin B1 expression (27). Additionally, the fact that $\mathrm{LiCl}$ did not reduce cell viability is in agreement with previous studies $(25,26)$.

Aberrant Wnt activation has been observed in various types of cancer, including CRC (40); and GSK3- $\beta$ inhibitors, such as lithium, may either promote or prevent cancer progression. In this study, colony formation and cell motility assays were used to measure the tumorigenic potential after the different treatments. The colony growth assay showed that EGF did not have any effect on the capacity of Caco-2 cells to form colonies compared to untreated cells, whereas lithium reduced colony formation after 10 days of treatment. However, EGF increased cell migration at $24 \mathrm{~h}$, and lithium inhibited this effect. EGF has been shown to be able to induce cell migration in a hamster ovary cell line (CHO), mouse embryonic stem cells, and in cultures of human lens epithelial cells (41-44). Our results indicating that lithium inhibits cell migration after $48 \mathrm{~h}$ of treatment are in agreement with those of other studies using cell lines other than tumor cancer cells (45). Taken together, these results support the idea that lithium has tumor suppressor activity.

In conclusion, our findings show that EGF and lithium causes the internalization of $\beta$-catenin and claudin- 1 from the cell-cell contacts to the cytoplasm and nucleus. Although EGF caused $\beta$-catenin nuclear localization, it did not inhibit the enzyme GSK3- $\beta$. Furthermore, lithium treatment blocked the increase in cell proliferation by $\mathrm{G}_{2} / \mathrm{M}$ cell cycle arrest as well as the cell migration that was induced by EGF treatment. Thus, our results suggest that lithium, by inhibiting the tumorigenic effects of EGF, may have tumor suppressor activity in CRC.

\section{Acknowledgments}

This study was supported by Ministério da Saúde (MS-Brazil), Fundação Carlos Chagas Filho de Amparo à Pesquisa do Estado do Rio de Janeiro (FAPERJ), Conselho Nacional de Desenvolvimento Científico e Tecnológico (CNPq), and Programa de Cooperação INCA/FIOCRUZ. This text was reviewed by the American Journal Experts.

\section{References}

1. Cereijido M, Contreras RG, Shoshani L, Flores-Benitez D and Larre I: Tight junction and polarity interaction in the transporting epithelial phenotype. Biochim Biophys Acta 1778: 770-793, 2008.

2. Giepmans BN and van Ijzendoorn SC: Epithelial cell-cell junctions and plasma membrane domains. Biochim Biophys Acta 1788: 820-831, 2009.

3. Gavert $\mathrm{N}$ and Ben-Ze'ev A: Epithelial-mesenchymal transition and the invasive potential of tumors. Trends Mol Med 14: 199-209, 2008

4. Yamada T, Takaoka AS, Naishiro Y, et al: Transactivation of the multidrug resistance 1 gene by T-cell factor $4 /$ beta-catenin complex in early colorectal carcinogenesis. Cancer Res 60: 4761-4766, 2000.

5. Huang D and Du X: Crosstalk between tumor cells and microenvironment via Wnt pathway in colorectal cancer dissemination. World J Gastroenterol 14: 1823-1827, 2008.

6. Singh AB and Harris RC: Epidermal growth factor receptor activation differentially regulates claudin expression and enhances transepithelial resistance in Madin-Darby canine kidney cells. J Biol Chem 279: 3543-3552, 2004. 
7. Dhawan P, Singh AB, Deane NG, et al: Claudin-1 regulates cellular transformation and metastatic behavior in colon cancer. J Clin Invest 115: 1765-1776, 2005.

8. Hewitt KJ, Agarwal R and Morin PJ: The claudin gene family: expression in normal and neoplastic tissues. BMC Cancer 12 : $186,2006$.

9. Mees ST, Mennigen R, Spieker T, Rijcken E, Senninger N, Haier $\mathbf{J}$ and Bruewer $\mathrm{M}$ : Expression of tight and adherens junction proteins in ulcerative colitis associated colorectal carcinoma: upregulation of claudin-1, claudin-3, claudin- 4 , and beta-catenin. Int J Colorectal Dis 24: 361-368, 2009.

10. Takehara M, Nishimura T, Mima S, Hoshino T and Mizushima T: Effect of claudin expression on paracellular permeability migration and invasion of colonic cancer cells. Biol Pharm Bull 32: 825-831, 2009.

11. Jemal A, Siegel R, Ward E, Murray T, Xu J and Thun MJ: Cancer statistics, 2007. Cancer J Clin 57: 43-66, 2007.

12. Flores-Benítez D, Ruiz-Cabrera A, Flores-Maldonado C Shoshani L, Cereijido $\mathrm{M}$ and Contreras RG: Control of tight junctional sealing: role of epidermal growth factor. Am J Physiol Renal Physiol 292: F828-F836, 2007.

13. Flores-Benitez D, Rincon-Heredia R, Razgado LF, Larre I Cereijido $\mathrm{M}$ and Contreras RG: Control of tight junctional sealing: roles of epidermal growth factor and prostaglandin E2. Am J Physiol Cell Physiol 297: C611-C620, 2009.

14. Yoshida K, Kanaoka S, Takai T, Uezato T, Miura N, Kajimura M and Hishida A: EGF rapidly translocates tight junction proteins from the cytoplasm to the cell-cell contact via protein kinase C activation in TMK-1 gastric cancer cells. Exp Cell Res 309: 397-409, 2005.

15. Hanahan D and Weinberg RA: The hallmarks of cancer. Cell 100: 57-70, 2000.

16. Grände M, Franzen A, Karlsson JA, Ericson LE, Heldin NE and Nilsson M: Transforming growth factor-beta and epidermal growth factor synergistically stimulate epithelial to mesenchymal transition (EMT) through a MEK-dependent mechanism in primary cultured pig thyrocytes. J Cell Sci 115: 4227-4236, 2002.

17. Lu Z, Ghosh S, Wang Z and Hunter T: Downregulation of caveolin-1 function by EGF leads to the loss of E-cadherin, increased transcriptional activity of $\beta$-catenin, and enhanced tumor invasion. Cancer Cell 4: 499-515, 2003.

18. Grimes CA and Jope RS: The multifaceted roles of glycogen synthase kinase 3beta in cellular signaling. Prog Neurobiol 65 : 391-426, 2001

19. Ding Q, Xia W, Liu JC, et al: Erk associates with and primes GSK-3beta for its inactivation resulting in upregulation of betacatenin. Mol Cell 22: 159-170, 2005.

20. Caraci F, Gili E, Calafiore M, et al: TGF-betal targets the GSK-3beta/beta-catenin pathway via ERK activation in the transition of human lung fibroblasts into myofibroblasts. Pharmacol Res 57: 274-282, 2008.

21. Mizushima T, Nakagawa H, Kamberov YG, Wilder EL, Klein PS and Rustgi AK: Wnt-1 but not epidermal growth factor induces beta-catenin/T-cell factor-dependent transcription in esophageal cancer cells. Cancer Res 62: 277-282, 2002

22. Taylor JA, Bernabe KQ, Guo J and Warner BW: Epidermal growth factor receptor-directed enterocyte proliferation does not induce Wnt pathway transcription. J Pediatr Surg 42: 981-986, 2007.

23. Ryves WJ and Harwood AJ: Lithium inhibits glycogen synthase kinase- 3 by competition for magnesium. Biochem Biophys Res Commun 26: 720-725, 2001

24. Pardo R, Andreolotti AG, Ramos B, Picatoste F and Claro E: Opposed effects of lithium on the MEK-ERK pathway in neural cells: inhibition in astrocytes and stimulation in neurons by GSK3 independent mechanisms. J Neurochem 87: 417-426, 2003.

25. Stump RJ, Lovicu FJ, Ang SL, Pandey SK and McAvoy JW: Lithium stabilizes the polarized lens epithelial phenotype and inhibits proliferation, migration, and epithelial mesenchymal transition. J Pathol 210: 249-257, 2006.

26. Sun A, Shanmugam I, Song J, Terranova PF, Thrasher JB and Li B: Lithium suppresses cell proliferation by interrupting E2F-DNA interaction and subsequently reducing S-phase gene expression in prostate cancer. Prostate 67: 976-988, 2007.
27. Wang JS, Wang CL, Wen JF, Wang YJ, Hu YB and Ren HZ Lithium inhibits proliferation of human esophageal cancer cell line Eca-109 by inducing a G2/M cell cycle arrest. World J Gastroenterol 14: 3982-9398, 2008

28. Bowley E, Mulvihill E, Howard JC, Pak BJ, Gan BS and O'Gorman DB: A novel mass spectrometry-based assay for GSK-3 $\beta$ activity. BMC Biochem 16: 29, 2005

29. Leve F, Souza W and Morgado-Díaz JA: A cross-link between protein kinase A and Rho-family GTPases signaling mediates cell-cell adhesion and actin cytoskeleton organization in epithelial cancer cells. J Pharmacol Exp Ther 327: 777-788, 2008.

30. Tanaka MN, Diaz BL, Souza W and Morgado-Díaz JA: Prostaglandin E2-EP1 and EP2 receptor signaling promotes apical junctional complex disassembly of Caco-2 human colorectal cancer cells. BMC Cell Biol 9: 63, 2008.

31. Tsuji T, Ibaragi S and Hu GF: Epithelial-mesenchymal transition and cell cooperativity in metastasis. Cancer Res 69: 7135-7139, 2009.

32. Colomiere M, Ward AC, Riley C, et al: Cross talk of signals between EGFR and IL-6R through JAK2/STAT3 mediate epithelial-mesenchymal transition in ovarian carcinomas. Br J Cancer 13: 134-144, 2009.

33. Leotlela PD, Wade MS, Duray PH, et al: Claudin-1 overexpression in melanoma is regulated by PKC and contributes to melanoma cell motility. Oncogene 26: 3846-3856, 2007.

34. De Oliveira SS, de Oliveira IM, de Souza W and Morgado-Díaz JA: Claudins upregulation in human colorectal cancer. FEBS Lett 579: 6179-6185, 2005

35. Sinha D, Wang Z, Ruchalski KL, et al: Lithium activates the Wnt and phosphatidylinositol 3-kinase Akt signaling pathways to promote cell survival in the absence of soluble survival factors. Am J Physiol Renal Physiol 288: F703-F713, 2005.

36. Eldar-Finkelman H, Seger R, Vandenheede JR and Krebs EG: Inactivation of glycogen synthase kinase- 3 by epidermal growth factor is mediated by mitogen-activated protein kinase/p90 ribosomal protein S6 kinase signaling pathway in NIH/3T3 cells. J Biol Chem 270: 987-990, 1995.

37. Krugluger W, Seidel S, Steindl K and Binder S: Epidermal growth factor inhibits glycogen synthase kinase-3 (GSK-3) and beta-catenin transcription in cultured ARPE-19 cells. Graefes Arch Clin Exp Ophthalmol 245: 1543-1548, 2007.

38. Yarden Y: The EGFR family and its ligands in human cancer signaling mechanisms and therapeutic opportunities. Eur J Cancer 4: S3-S8, 2001.

39. Normanno N, De Luca A, Bianco C, et al: Epidermal growth factor receptor (EGFR) signaling in cancer. Gene 17: 2-16, 2006.

40. Reya $\mathrm{T}$ and Clevers $\mathrm{H}$ : Wnt signalling in stem cells and cancer. Nature 14: 843-850, 2005

41. Harms BD, Bassi GM, Horwitz AR and Lauffenburger DA: Directional persistence of EGF-induced cell migration is associated with stabilization of lamellipodial protrusions. Biophys $\mathbf{J} 88$ : $1479-1488,2005$

42. Jiang Q, Zhou C, Bi Z and Wan Y: EGF-induced cell migration is mediated by ERK and PI3K/AKT pathways in cultured human lens epithelial cells. J Ocul Pharmacol Ther 22: 93-102, 2006.

43. Wu Y, Shang Y, Sun S, Liang H and Liu R: Erythropoietin prevents PC12 cells from 1-methyl-4-phenylpyridinium ioninduced apoptosis via the Akt/GSK-3beta/caspase-3 mediated signaling pathway. Apoptosis 12: 1365-1375, 2007.

44. Park JH and Han HJ: Caveolin-1 plays important role in EGF-induced migration and proliferation of mouse embryonic stem cells: Involvement of PI3K/Akt and ERK. Am J Physiol Cell Physiol 297: C935-C944, 2009.

45. Zaragosi LE, Wdziekonski B, Fontaine C, Villageois P, Peraldi P and Dani C: Effects of GSK3 inhibitors on in vitro expansion and differentiation of human adipose-derived stem cells into adipocytes. BMC Cell Biol 13: 9-11, 2008. 